\title{
Fetomaternal outcome of eclamptic parturient in a tertiary care center: A descriptive cross-sectional study
}

\author{
Aashika Shrestha', Junu Shrestha², Sangeeta Gurung ${ }^{3}$, Anjali Subedi Adhikari ${ }^{3}$ \\ ${ }^{1}$ Lecturer, ${ }^{2}$ Associate Professor, ${ }^{3}$ Assistant Professor, Department of Obstetrics and Gynecology, Manipal College of
} Medical Sciences

Background: Eclampsia is still a leading cause of maternal death second to postpartum hemorrhage in developing countries. It is also associated with poor perinatal outcome. Aims and Objective: The objective of this study was to find the incidence, maternal and perinatal outcome of patients admitted in a tertiary hospital, Pokhara with diagnosis of eclampsia. Materials and Methods: A descriptive cross sectional study was conducted in department of obstetrics and gynecology, MTH, Pokhara for duration of 1 year from $1^{\text {st }}$ January 2020 to $30^{\text {th }}$ December 2020. A total of 22 patients were enrolled in the study irrespective of timing of occurrence of fits, age, parity, gestational age and status of booking on admission. Results: During the study period the incidence of eclampsia at our center was $0.85 \%$. Majority of the patients $17(77.27 \%$ ) were primigravida and $16(72.68 \%)$ delivered at less than 37 weeks of gestation. Only 4 patients had her antenatal checkup done in MTH. According to timing of occurrence of fits Antepartum and postpartum eclampsia comprise $50 \%$ each with no cases of intrapartum eclampsia. Caesarean section was done in $17(77 \%)$ cases. Among the cases 10 , $(45.45 \%)$ patients required ICU admission and 6(27.27\%) required ventilator support. HELLP, acute renal failures, PRES, PPH were causes of maternal morbidity. Three $(13.63 \%)$ babies were born stillbirth. Sixteen (72.72\%) babies were born preterm and 13(59.09\%) had birth weight less than $2.5 \mathrm{~kg}$. Six $(27.27 \%)$ babies needed NICU admission. Conclusion: Eclampsia continues to be one of the prime etiological factors for maternal and perinatal morbidity and mortality in developing countries like ours. This is mostly due to the delay in seeking and reaching the care. Regular antenatal checkup, early recognition, its prevention and proper management of eclamptic cases are vital to tackle this challenge.

Key words: Eclampsia; Maternal outcome; Perinatal outcome

\section{INTRODUCTION}

Preeclampsia (PE) and eclampsia are the second leading causes claiming 46,900 maternal deaths worldwide ${ }^{1}$ Eclampsia is characterized by new onset of grand mal seizure activity and/or unexplained coma during pregnancy or postpartum in a woman with signs or symptoms of preeclampsia and is one of the serious obstetric emergency. ${ }^{2}$ Women often presents with few warning signs and even occurs in a women with previously mild disease and therefore predicting its occurrence is as difficult as predicting the timing. ${ }^{3}$ The incidence of eclampsia is on decreasing trend in developed countries but it's still a leading cause of maternal death second to postpartum hemorrhage in developing countries. The crude incidence of eclampsia fluctuates from 0 to $0.1 \%$ in Europe and up to $4 \%$ in Nigeria ${ }^{4} 0.6 \%$ in Brazil, ${ }^{5}$ in India it varies from 0.18 to $4.6 \%{ }^{6}$ In several studies done in Nepal the incidence varied from $.29 \%$ to $1.3 \% .^{7-9}$ This variation emphasizes the huge gap in quality of maternal health care.

Eclampsia has been one of the leading causes of maternal and perinatal mortality as well as morbidity throughout the world. Maternal death rates of 0 to $13.9 \%$ have been reported. ${ }^{10}$ and it is estimated that around 50000 maternal 
deaths per year worldwide occurs due to eclampsia, with the large majority of cases occurring in developing countries. ${ }^{11}$

The perinatal death rate in this condition is closely related to gestational age and varies from 90 to 230 per 1000 deliveries worldwide. ${ }^{10}$ The British eclampsia survey reported associated stillbirth and neonatal death rates of 22.2 per 1000 deliveries and 34.1 per 1000 deliveries. ${ }^{12}$

Though all cases of eclampsia cannot be prevented but effort can be made to reduce maternal and perinatal morbidity and mortality by reinforcing women for basic four or more antenatal visit, giving proper information about danger signs in pregnancy and where to go in case of danger signs and benefit of postnatal care. In developing country like ours though there has been a substantial progress in improvement of maternal health care access and utilization, disparities still remains according to women's socioeconomic status, education level and place of residence. So, additional efforts are needed to improve the quality of maternal health care to end preventable maternal death due to eclampsia. This study aims to find the incidence and analyze cases of eclampsia in relation to maternal and fetal outcome.

\section{Aims and objectives}

1. To find out the incidence of eclampsia in tertiary care center

2. To study the maternal and fetal outcome of patients with Eclampsia.

\section{Inclusion criteria}

All cases of antepartum, intrapartum and postpartum eclampsia admitted in maternity ward of a teaching hospital.

\section{Exclusion criteria}

Other causes of convulsion with pregnancy like epilepsy, meningitis, cerebrovascular accidents and patient presenting after 7 days of delivery.

\section{MATERIALS AND METHODS}

It was a cross sectional hospital based study conducted in department of obstetrics and gynecology, Manipal Teaching Hospital, Pokhara. The study period was of 1 year starting from January 2020 to December 2020. Ethical approval was taken from the ethical committee of Manipal teaching hospital and verbal consent for study was taken from patient party or patient herself if conscious and oriented.

Hypertensive patients with tonic clonic convulsion either antepartum, intrapartum or postpartum irrespective of their age, gestational age, parity and status of booking on admission were included in the study. A detailed history was taken from attendant or patient herself regarding age, parity, gestational age, ANC checkup during pregnancy, any rise of $\mathrm{BP}$ during pregnancy, whether she was on antihypertensive medication, type and nature of convulsion, the number of convulsion before admission, and events prior to convulsions like a headache, epigastric pain, vomiting, blurring of vision. Thorough examination of patient was done and investigations sent. Pritchard's regimen was followed and loading dose of 14 gms i.e. 4 gms IV slowly over 3-5 minutes and $10 \mathrm{gm}$ deep intramuscular was given if not received previously. Anti-hypertensive started if blood pressure exceeded 140/90 mmHg. Once patient was stabilized mode of delivery was decided. Caesarean section was done if induction failed or for other obstetrical indications. Choice of anesthesia was decided by anesthetist. All newborn babies were examined immediately by pediatrician after delivery. A woman in need of ICU and ventilatory support was shifted to ICU. In cases of complication, respective specialist was involved in the management. Maintenance dose of Magnesium sulphate and antihypertensive was continued. Mother and neonate were followed till the time of discharge. Statistical analysis was done using SPSS version 20.0 using simple descriptive statistics. Data were analyzed in term of percentage and presented in tabulated and figure form.

\section{RESULT}

During the study period of one year 2559 patients attended our institute for obstetric care out of which 22 patient were cases of eclampsia which gives an incidence of $0.85 \%$.

The result of demographic profile depicted in Table 1 show that most of the women who had eclampsia were less than 30 years of age. Among them 18.1\% were teen pregnancies and only $4.5 \%$ of case were above 30 years. Majority of patient ( $\mathrm{n}=16,72.68 \%)$ delivered at less than 37 weeks of gestation. Only 6(27.27\%) patient delivered at term and $(\mathrm{n}=17,77.27 \%)$ were primipara and only $(\mathrm{n}=5$, $22.72 \%$ ) were multipara (Table 1).

The booking status of patients reveals that only $4(18.18 \%)$ patients had antenatal care in Manipal. Majority of patient $12(54.54 \%)$ had antenatal care in either other institute or primary health care Centre. Six patients $(27.27 \%)$ had no antenatal visit throughout her pregnancy (Table 2).

Blood pressure recorded at the time of admission as shown in Table 3 were categorized in terms of systolic and diastolic BP. In 12(54.54\%) patients Systolic blood pressure was more than $160 \mathrm{mmHg}$ whereas in $3(13.63 \%)$ patients it was less than $140 \mathrm{mmHg}$. In $3(13.63 \%)$ cases diastolic blood pressure was less than $90 \mathrm{mmHg}$ whereas in $13(59.09 \%)$ cases it ranged between $90-110 \mathrm{mmHg}$. In 6(27.27\%) cases it was more than $110 \mathrm{mmHg}$ (Table 3). 


\begin{tabular}{|c|c|c|}
\hline Demographic profile & Total number of patients & $\%$ \\
\hline \multicolumn{3}{|l|}{ Maternal age } \\
\hline$\leq 20$ years & 4 & $18.1 \%$ \\
\hline $21-30$ years & 17 & $77.27 \%$ \\
\hline$>30$ years & 1 & $4.5 \%$ \\
\hline \multicolumn{3}{|l|}{ Gestational age } \\
\hline$<34$ weeks & 1 & $4.5 \%$ \\
\hline 34-37 weeks & 15 & $68.18 \%$ \\
\hline >37 weeks & 6 & $27.27 \%$ \\
\hline \multicolumn{3}{|l|}{ Parity } \\
\hline Primipara & 17 & $77.27 \%$ \\
\hline Multipara & 5 & $22.72 \%$ \\
\hline
\end{tabular}

\begin{tabular}{lcc}
\multicolumn{3}{l}{ Table 2: Distribution according to booking status } \\
\hline Booking status & Total number of patients & $\%$ \\
\hline ANC in Manipal & 4 & $18.18 \%$ \\
ANC elsewhere & 12 & $54.54 \%$ \\
No Antenatal care & 6 & $27.27 \%$ \\
\hline
\end{tabular}

\begin{tabular}{lcc}
\multicolumn{2}{l}{$\begin{array}{l}\text { Table 3: Distribution according to BP at the time } \\
\text { of admission }\end{array}$} \\
\hline $\begin{array}{l}\text { BP at the time } \\
\text { of admission }\end{array}$ & $\begin{array}{c}\text { Total number } \\
\text { of patients }\end{array}$ & $\%$ \\
\hline $\begin{array}{c}\text { Systolic BP } \\
<140 \mathrm{mmHg}\end{array}$ & 3 & $13.63 \%$ \\
$140-160 \mathrm{mmHg}$ & 7 & $31.81 \%$ \\
$>160 \mathrm{mmHg}$ & 12 & $54.54 \%$ \\
Diastolic BP & & \\
$<90 \mathrm{mmHg}$ & 3 & $13.63 \%$ \\
$90-110 \mathrm{mmHg}$ & 13 & $59.09 \%$ \\
$>110 \mathrm{mmHg}$ & 6 & $27.27 \%$ \\
\hline
\end{tabular}

\begin{tabular}{lcc} 
Table 4: Hospital care & \\
\hline Hospital care & Total number of patients & $\%$ \\
\hline ICU care & 10 & $45.45 \%$ \\
Post-Operative room & 12 & $54.54 \%$ \\
Ventilatory support & 6 & $27.27 \%$ \\
\hline
\end{tabular}

According to the period of occurrence of fits, Antepartum eclampsia was present in $11(50 \%)$ cases and rest $11(50 \%)$ had eclampsia in postpartum period (Figure 1).

Most of the cases $17(77.27 \%)$ underwent caesarean section and only $5(22.72 \%$ ) patients delivered vaginally (Figure 2 ).

Almost half of the cases $10(45.45 \%)$ were admitted in ICU for monitoring whereas $12(54.54 \%)$ received care in Post-operative ward. Six (27.27\%) patient were kept under ventilatory support (Table 4).

Regarding maternal morbidity $3(13.63 \%)$ patient had HELLP syndrome, 1(4.54\%) had acute renal failure, $3(13.63 \%)$ had posterior reversible encephalopathy syndrome, 4(18.18\%) had post-partum hemorrhage and

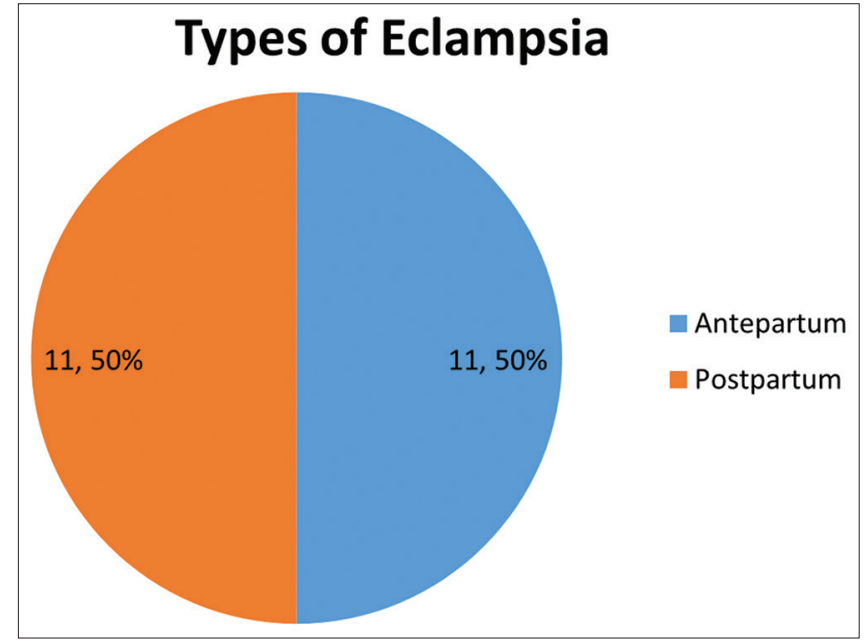

Figure 1: Distribution of study group according to period of occurrence of fits

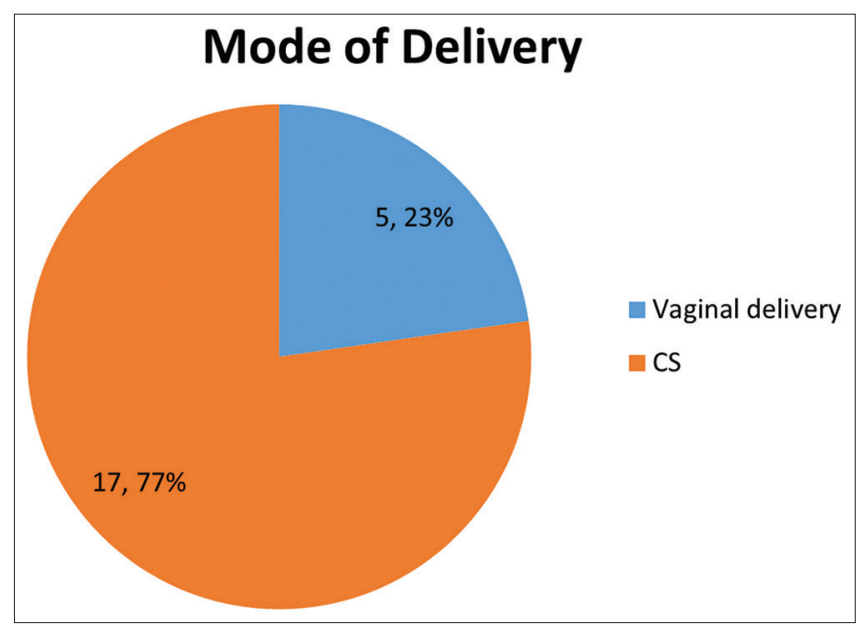

Figure 2: Distribution of study group according to mode of delivery

\begin{tabular}{lcc}
\multicolumn{3}{l}{ Table 5: Maternal morbidity } \\
\hline Maternal morbidity & Total number of patients & $\%$ \\
\hline HELLP syndrome & 3 & $13.63 \%$ \\
Acute renal failure & 1 & $4.54 \%$ \\
PRES & 3 & $13.63 \%$ \\
PPH & 4 & $18.18 \%$ \\
Psychosis & 1 & $4.54 \%$ \\
\hline
\end{tabular}

\begin{tabular}{lcc} 
Table 6: Perinatal outcome & & \\
\hline Perinatal outcome & No. & $\%$ \\
\hline Live birth & 19 & $86.36 \%$ \\
Still birth & 3 & $13.63 \%$ \\
Term & 6 & $27.27 \%$ \\
Preterm & 16 & $72.72 \%$ \\
Body Weight $>2.5 \mathrm{~kg}$ & 9 & $40.90 \%$ \\
Low birth weight $<2.5 \mathrm{~kg}$ & 13 & $59.09 \%$ \\
NICU admission & 6 & $27.27 \%$ \\
\hline
\end{tabular}

1(4.54\%) had psychosis. No maternal mortality was present during the study period (Table 5). 
Perinatal outcome depict that $19(86.36 \%)$ patients had live birth and 3(13.63\%) had stillbirth. Six (27.27\%) babies were delivered at term and 16(72.72\%) delivered preterm. Thirteen $(59.09 \%)$ babies born were low birth weight and $9(40.90 \%)$ had birth weight $>2.5 \mathrm{~kg}$. Six $(27.27 \%)$ babies needed NICU admission (Table 6).

\section{DISCUSSION}

This study showed that the hospital based incidence of eclampsia was $0.85 \%$ which is similar to studies done by Dalal et $\mathrm{al}^{13}$ which was $0.96 \%$ and Verma et $\mathrm{al}^{14} 0.82 \%$. However it was lower than the incidence shown in various studies which ranged from $1.1 \%$ to $1.58 \% \cdot{ }^{15-20}$ Studies done in developed countries showed the incidence to be from $0.29 \%$ to $0.79 \%$. This can be due to provision of better antenatal care. ${ }^{21}$

Eclampsia is found to affect young and nulliparous women. In our study most of the women $17(77.27 \%$ ) belonged to age group of 20-30 years. Four (18.1\%) women were less than 20 years and only one woman was more than 30 years. Similar finding was observed by Dalal et al ${ }^{13}$ where $56 \%$ of the patient belonged to the age group of 21-25 years and only $2.6 \%$ women were more than 30 years. In a study done by Verma et al ${ }^{14} 160(46.15 \%)$ women were between $21-25$ years and only $5.38 \%$ women were $>30$ years. Similar finding were observed in many otherstudies. ${ }^{17,20}$

It was found that 17 (77.27\%) women were primipara. Most of the studies showed similar finding. $13,14,17,20$ The exact mechanism for occurrence of eclampsia in nulliparous women is still unknown though various postulations have been made. During antenatal checkup this high risk group needs strict screening and they should be educated about the importance of regular blood pressure monitoring and about the warning symptoms.

In our study only $18.18 \%$ of women were booked at Manipal whereas $54.54 \%$ women had visited nearby health facilities at least once. Among them $27 \%$ of women had never attended any health care facility for their antenatal checkup. Lack of regular antenatal care was found in most of the cases. In a study done by Sujata et $\mathrm{al}^{20} 55.7 \%$ women had no antenatal care and only $34.61 \%$ had regular antenatal care. Dalal et $\mathrm{al}^{13}$ and Verma et $\mathrm{al}^{14}$ in their studies also found that most of the women were unbooked cases. This result shows lack of awareness among the women regarding the importance of antenatal care. If major focus is given on regular antenatal checkup than most of the cases of eclampsia can be prevented.

In our study $68.18 \%$ cases had gestational age less than 37 weeks which is similar to study done by Kamrun $\mathrm{N}$ et al ${ }^{16}$ where $62.85 \%$ were preterm cases. Regarding timing of occurrence of fits $50 \%$ cases had fits in antenatal period and $50 \%$ in postpartum period. This is in contrast to most of the studies which showed antepartum period to be the most common time for occurrence of fits. Few studies showed incidence of postpartum eclampsia to be comparable or slightly higher than in our study. ${ }^{16}$

Elevated blood pressure is the most crucial parameter to diagnose pre eclampsia and eclampsia. In our study $12(54.54 \%)$ patient had systolic blood pressure $>160 \mathrm{mmHg}$ and few patient $3(13.63 \%)$ even had BP $<140 \mathrm{mmHg}$. Similarly 13(59.09\%) patient had diastolic BP between 90-110mmHg, 6(27.27\%) had $>110 \mathrm{mmHg}$ and $3(13.63 \%)$ had $<90 \mathrm{mmHg}$. Women who had postpartum eclampsia were found to have near normal blood pressure range than in women who had antepartum eclampsia. This shows that in most of the cases women who are prone to develop eclampsia have significantly raised blood pressure but it even occurred in women with normal range blood pressure. Dalal et $\mathrm{al}^{13}$ in her study found that in $14 \%$ of the cases blood pressure were within normal range. Similarly Verma et $\mathrm{al}^{14}$ found that in $13.85 \%$ cases systolic BP was $<140 \mathrm{mmHg}$ and in $6.15 \%$ cases diastolic BP was $<90 \mathrm{mmHg}$.

In our study $17(77 \%)$ women underwent emergency caesarean section and $5(22.72 \%)$ had vaginal delivery. Most of the women who underwent caesarean were cases of antepartum eclampsia and they were either remote from term with unfavorable cervix or with other obstetric indications for caesarean. Most of the studies showed similar findings. Contrary to our study $71.54 \%$ cases had vaginal delivery in a study done by Verma et a ${ }^{14}$ Eclampsia per se is not the sole indication for caesarean section but timely and judicious selection of cases for vaginal or caesarean is said to improve maternal as well as fetal outcome.

Regarding hospital care $45.45 \%$ patient required intensive care monitoring whereas $54.54 \%$ patient were monitored in post-operative ward. Ventilatory support was required in $27.27 \%$ cases. Most of the ventilated patients had repeated episode of seizure and could not be extubated. Similar finding was reported by Kamrun $\mathrm{N}$ et al ${ }^{16}$ where $40 \%$ patient received ICU care and $51.42 \%$ were treated in eclampsia ward. In a study done by Dalal et al., ${ }^{13} 24.77 \%$ patient required ICU care and Pradhan et $\mathrm{al}^{22}$ reported that 31 patient out of 52 required ventilator support for respiration. These findings warrant urgent need of referral of all cases of eclampsia to tertiary care center.

In terms of maternal morbidity $3(13.63 \%)$ patients suffered from HELLP Syndrome, 1(4.54\%) had acute renal failure, $3(13.63 \%)$ had posterior reversible encephalopathy syndrome,4(18.88\%) had postpartum hemorrhage and 
$1(4.54 \%)$ had psychosis. No maternal mortality occurred due to the complication of eclampsia during the study period. Most of the studies showed similar causes for maternal morbidity and mortality. ${ }^{5,14,19,20}$ Morbidities were more commonly seen in patients who were in critical condition at the time of arrival to hospital, delayed referred cases, and delay in seeking and reaching care due to poor transport facilities and inadequate diagnosis and treatment at peripheral centers and most of them did not receive any antenatal care.

There were $3(13.63 \%)$ perinatal death and all were stillbirth cases. Similar finding was noted in study done by Jadav et $\mathrm{al}^{18}$ where $15 \%$ of babies born were stillbirth and $11 \%$ in a study done by Pradhan et al. ${ }^{22}$ Most of the baby's i.e. $72.72 \%$ were delivered preterm and $59.09 \%$ were of low birth weight. This result is comparable to studies done by Sujata et $\mathrm{al}^{20}$ where $60 \%$ of the newborn were low birth weight. Six (27.27\%) babies needed NICU admission for various indications and were discharged after receiving treatment.

\section{CONCLUSION}

Eclampsia still is a second leading cause of maternal death and remains an intractable obstetric emergency in the underprivileged world. Studies shows that young women who are pregnant for the first time and who receive inadequate antenatal care are the major contributors to the poor outcome of eclamptic women. Educating young women about the need of basic antenatal care, improving quality of service at primary health care level by educating all health care workers about the importance of identifying high risk cases and close supervision of those cases and timely intervention and provision for early and safe referral will help to improve maternal and fetal outcome in eclampsia.

\section{ACKNOWLEDGEMENT}

We would like to thank the hospital administration for allowing us to conduct the study in the hospital. We also like to acknowledge the help and cooperation from patient, family members and staffs of hospital.

\section{REFERENCES}

1. Wang H, Naghavi M, Allen C, Barber R, Bhutta Z, Carter A, et al. Global, Regional, And National Life Expectancy, All-Cause Mortality, And Cause-Specific Mortality For 249 Causes Of Death, 1980-2015: A Systematic Analysis For The Global Burden Of Disease Study 2015. Lancet. 2016; 388(10053):1459-1544. https://doi.org/10.1016/S0140-6736(16)31012-1

2. American College of Obstetricians and Gynecologists, Task Force on Hypertension in Pregnancy. Hypertension in pregnancy. Report of the American College of Obstetricians and Gynecologists' Task Force on Hypertension in Pregnancy. Obstet Gynecol. 2013; 122:1122.

https://doi.org/10.1097/01.AOG.0000437382.03963.88

3. Onwuhafua PI, Onwuhafua A, Adze J and Mairami Z. Eclampsia in Kaduna State of Nigeria. A Proposal for Better Outcome. Niger J Med. 2001; 10(2):81-84. PMID: 11705065.

4. Konje JC, Obisesan KA, Odukoya OA and Ladipo OA. Presentation and Management Of Eclampsia. Int J Gynaecol Obstet. 1992; 38:31-35. https://doi.org/10.1016/0020-7292(92)90726-Y

5. Abalos E, Cuesta C, Grosso A, Chou D and Say L. Global and Regional Estimates Of Preeclampsia And Eclampsia: A Systematic Review. Eur J Obstet Gynecol. 2013; 170(1):1-7. https://doi.org/10.1016/j.ejogrb.2013.05.005

6. Varawalla NY, Ghamande S and Kumud MI. A Five Year Analysis Of Eclampsia. J Obstet Gynaecol India. 1989; 39:513-515.

7. Choudhary P. Eclampsia: A Hospital Based Retrospective Study. Kathmandu Univ Med J. 2003; 1: 237-241.

8. Regmi MC, Agrawal A, Pradhan T, Rijal P, Subedi A and Uprety D. Loading Dose Versus Standard Dose Regimen Of Magnesium Sulfate In Eclampsia- A Randomized Controlled Trial. Nepal Med Coll J. 2010; 12(4): 244-247.

9. Ghimire S. Eclampsia: Feto-Maternal Outcomes In A Tertiary Care Centre In Eastern Nepal. J Nepal Med Assoc.2016; 54(201):24-28.

https://doi.org/10.31729/jnma.2812

10. Norowitz ER, Hsu CD and Repke JT. Acute Complications Of Preeclampsia. Clin Obstet Gynecol. 2002; 45(2):308-329. https://doi.org/10.1097/00003081-200206000-00004

11. Duley L. Maternal Mortality Associated With Hypertensive Disorders Of Pregnancy In Africa, Asia, Latin America And The Caribbean. Br J Obstet Gynaecol. 1992; 99:547-553. https://doi.org/10.1111/j.1471-0528.1992.tb13818.x

12. Douglas KA and Redmond CWG. Eclampsia in the United Kingdom. BMJ. 1994; 309: 1395-1400. https://doi.org/10.1136/bmj.309.6966.1395

13. Dalal M, Singh S, Chauhan M, Nanda S, Dalal J and Madan J. Maternal And Perinatal Outcome In Eclampsia At A Tertiary Care Center. Int J Reprod Contracept Obstet Gynecol. 2019; 8(10):3898-3902. https://doi.org/10.18203/2320-1770.ijrcog20194350

14. Verma K, Baniya GC, Agrawal S and Lomrod S. A Study Of Maternal And Perinatal Outcome In Eclampsia Patients. Indian J Obstet Gynecol Res. 2016; 3(4):318-321. https://doi.org/10.7860/JCDR/2018/37432.12288

15. RC LK, Shrestha $S$ and Das CR. Managing Eclampsia In A Medical College.NJOG.2014; 17(1):74-77. https://doi.org/10.3126/njog.v9i1.11195

16. Kamrun N, Sanjida k, Selina B, Ferdowsi S and Tania A. Incidence and Fetomaternal Outcome of Eclampsia in a Tertiary Medical College Hospital in Bangladesh. The Journal of Medical Research. 2017; 17(2). DOI : 10.17406/GJMRA

17. Kurude VN, Kokate PH, Saha D and Jha EK. Study Of Maternal And Perinatal Outcome In Eclampsia. Indian Journal Of Research.2017; 6(4):63-65. https://doi.org/10.18203/2320-1770.ijrcog20194350

18. Jadav PK. Fetomaternal Outcome in Pregnancy with Eclampsia in Tertiary Care Hospital. Journal Of Medical Science And Clinical Research.2015; 3(7):6630-6635. https://doi.org/10.3126/jngmc.v15i2.22816 
19. Agida ET, Adeka $\mathrm{BI}$ and Jibril KA. Pregnancy Outcome In Eclamptics At The University Ofabuja Teaching Hospital, Gwagwalada, Abuja: A 3 Year Review. Nigerian Journal Of Clinical Practice. 2010; 13(4):394-398.

20. Pendyala $S$, Janmejaya $S$, Rajkumari $P$ and Gangadhar $S$. Maternal And Perinatal Outcome In Eclampsia. Journal Of Medical Science And Clinical Research.2016;4(11):14258-14263.

https://doi.org/10.18535/jmscr/v4i11.118
21. Chhabra S and Kakani A. Maternal Mortality Due To Eclamptic And Non-Eclamptic Hypertensive Disorders: A Challenge. J Obstet Gynaecol. 2007; 27:25-29.

https://doi.org/10.1080/01443610601016800

22. Pradhan T, Rijal P, Rai R, Bhatta RD, Thapa BD and Regmi MC. Adverse Maternal And Fetal Outcome In Patients With Eclampsia. J Nepal Health Res Counc. 2018; 16(41): 425-427. https://doi.org/10.33314/jnhrc.v16i41.1159

Author's Contribution:

AS-Concept and Design of the study, data collection Interpretation of results, Preparation of manuscript and revision of manuscript; JS, SGD, ASA-Revision of manuscript.

Work Attributed to:

Department of Obstetrics and Gynaecology, Manipal Teaching Hospital, Pokhara, Nepal.

Orcid ID:

Dr Aashika Shrestha - Dhttps://orcid.org/0000-0002-2738-6172

Dr Junu Shrestha - Dhttps://orcid.org/0000-0002-8683-2689

Dr Sangeeta Devi Gurung - ohttps://orcid.org/0000-0002-3288-1856

Dr Anjali Subedi - (iohttps://orcid.org/0000-0002-9809-6180

Source of Funding: None, Conflict of Interest: None 